\title{
Constraints to cabbage (Brassica oleracea var. capitata L.) production in peri-urban area of Saharsa district in Bihar
}

\section{AJEET KUMAR AND ASHWINI CHOUDHARY}

MEMBERS OF RESEARCH FORUM:

Corresponding author : AJEET KUMAR, Regional Research Station, Madhopur, WEST CHAMPARAN (BIHAR) INDIA Email: ajeetrau@gmail.com

Co-authors : ASHWINI CHOUDHARY, Department of Agricultural Economics, Mandan Bharti Agriculture College, AGWANPUR SAHARSA (BIHAR) INDIA
Received : 08.09.2016; Revised : 22.10.2016; Accepted : 17.11.2016

\section{Summary}

Vegetables are the integral part of the balanced diet of human since time immemorial. Globally, the role of vegetables has been recognized in solving the problem of food and nutritional security. A survey conducted to assemble baseline information on farming practices to cabbage production in peri-urban area of Saharsa district.Structured questionnaires used to elicit information from cabbage farmers, where cabbage is intensively produced. The level of education among the growers was low as only 6.67 per cent had secondary education. Majority of the growers $(68 \%)$ did not own the lands, thus, resulting in approximately 65 per cent of them cultivating less than one acre of cabbage. Majority of cabbage farmers $(61.67 \%)$ planted cabbage on raised beds. Cabbage production was characterized by high use of inorganic fertilizer (NPK). Seventy-three per cent farmers employed the watering cans in cabbage production. Farmers in their quest to mitigate the high insect pest infestation and problems such as wilting of plants, leaf curl and leaf spots resorted to high frequency of pesticides application. The information gathered from this study would form the basis for the formulation of an integrated pest management (IPM) as well as integrated nutrient management (INM) strategy to enhance environmentally sustainable production of cabbages. This would reduce environmental degradation and ensure maximum protection for human well being.

Key words : Constraints, Cabbage, pests, IPM

How to cite this article : Kumar, Ajeet and Choudhary, Ashwini (2016). Constraints to cabbage (Brassica oleracea var. capitata L.) production in peri-urban area of Saharsa district in Bihar. Asian J. Soil Sci., 11 (2) : 297-306 : DOI : 10.15740/HAS/AJSS/11.2/297-306. 